\title{
A APROPRIAÇÃO DA LEITURA E O SENTIDO DISCURSIVO DA LINGUAGEM ESCRITA
}

\author{
THE OWNERSHIP OF THE READING AND THE DISCURSIVE SENSE \\ OF WRITTEN LANGUAGE
}

\author{
Vanilda Gonçalves de Lima ${ }^{1}$ \\ Rede Municipal de Educação de Marília \\ vanildaestudante@gmail.com \\ Neire Márcia da Cunha ${ }^{2}$ \\ Universidade de Uberaba \\ neire.cunha@unibe.br
}

\section{RESUMO}

O trabalho visou refletir e analisar as concepções e procedimentos de ensino e aprendizagem da leitura e sua relação com a escrita a partir da Teoria Histórico-Cultural e do processo de leiturização de Jean Foucambert. A pesquisa caracterizou-se como qualitativa, com base nos estudos bibliográficos. A concepção de leitura defendida em ambas as abordagens se refere ao processo de construção e reconstrução do sentido discursivo dos signos culturais representados pela linguagem escrita. Concluiu-se que a leitura deve ser propiciada pelo professor com vistas à formação da criança como leitora e escritora de gêneros enunciativos. Assim, a leitura torna-se, de fato, reconhecida e valorizada como processo subjetivo de compreensão do discurso escrito da cultura humana.

Palavras-chave: Leitura. Leiturização. Sentido. Escrita.

\begin{abstract}
The work aimed to reflect and analyze the conceptions and procedures of teaching and learning to read and its relation with writing from the Historical-Cultural Theory and the reading process of Jean Foucambert. The research was characterized as qualitative, based on bibliographic studies. The conception of reading defended in both approaches refers to the process of construction and reconstruction of the discursive meaning of cultural signs represented by written language. It was concluded that reading should be provided by the teacher with a view to training the child as a reader and writer of enunciative genres. Thus, reading becomes, in fact, recognized and valued as a subjective process of understanding written discourse of human culture.
\end{abstract}

Keywords: Reading. Leiturização. Sense. Written. Understanding.

1 Coordenadora Pedagógica do Ensino Fundamental na Educação Municipal de Marília. Profa Preceptora Voluntária junto ao Projeto de Direitos Humanos e Gênero na escola.

2 Líder do Grupo de Estudos e Pesquisas Infância e Contextos Educativos. Assessora da Casa do Educador/ Secretaria de Educação de Marília. 


\section{Introdução}

A questão do processo de ensino e aprendizagem da leitura vem se tornando tema relevante de estudo e reflexão para muitos pesquisadores e professores preocupados com a formação leitora das crianças no contexto escolar. Com base nos pressupostos da Teoria Histórico-Cultural e na concepção de leitura defendida por Foucambert (1994), apresenta-se a seguinte questão: Como o processo de ensino e aprendizagem da leitura acontece no espaço escolar na perspectiva da formação da criança leitora e qual sua relação com a linguagem escrita? Assim sendo, o presente trabalho teve por objetivos refletir e analisar as concepções e procedimentos metodológicos de ensino e de aprendizagem da leitura e sua relação com a linguagem escrita de acordo com os pressupostos da Teoria Histórico-Cultural e estabelecer uma relação com a concepção de leitura e o processo de ensino e aprendizagem apresentada por Jean Foucambert $(1994,1997,2008)$, tendo em vista a formação do sujeito leitor na perspectiva da leiturização como prática de compreensão crítica do discurso escrito. A presente investigação caracteriza-se como bibliográfica fundamentada na abordagem da pesquisa qualitativa, pois resultou no levantamento, seleção, leitura e análise de referencial bibliográfico sobre a problemática de estudo (LÜDKE; ANDRE, 2013).

O texto encontra-se organizado da seguinte forma: primeiramente, apresenta-se uma reflexão acerca dos pressupostos da Teoria Histórico-Cultural, tendo em vista o processo de humanização do homem e suas implicações para a educação e formação da criança leitora. Na sequência, apresenta-se uma análise da perspectiva conceitual e metodológica do processo de ensino e de aprendizagem da leitura conforme as contribuições teóricas de Jean Foucambert $(1994,1997,2008)$ no sentido de reconhecermos a leitura como elemento cultural para a compreensão crítica da linguagem escrita.

Nesse sentido, a superação da problemática da educação brasileira em relação às capacidades leitoras de nossas crianças se apresenta como sendo, ainda, um desafio para todos os profissionais preocupados com a qualidade da educação, bem como com o desenvolvimento integral do ser humano, que precisa ser enfrentada por meio de uma sólida formação teórica e em práticas pedagógicas concretas em sala de aula.

\section{A Teoria Histórico-Cultural e suas implicações no processo de educação e humanização}

A Teoria Histórico-Cultural (THC) apresenta um dos pressupostos centrais para compreendermos o processo de humanização do Homem a partir do princípio de que se constitui nas relações sociohistóricas e culturais, pois este não nasce humano e, sim, se torna Homem nas relações que estabelece com o outro em sociedade.

O processo de humanização do Homem inicia-se com a apropriação das capacidades e aptidões já desenvolvidas pela espécie humana ao longo do desenvolvimento histórico. Ao nascer, o sujeito histórico não traz, geneticamente, as propriedades (capacidades, e aptidões) necessárias ao seu pleno desenvolvimento humano, social e cultural. Mas, necessita se apropriar, reproduzir e inovar essas propriedades humanas por meio das relações socioculturais estabelecidas com o outro a partir do convívio em sociedade. 
Como processo de humanização do homem constitui-se, essencialmente, em um processo de educação, como ressalta Leontiev (1978) quando considera que este somente se torna humano a partir da apropriação das propriedades humanas já desenvolvidas pelas gerações precedentes. Assim sendo, as relações socioculturais estabelecidas entre os homens se apresentam como condições concretas de apropriação e reprodução ativa das capacidades e aptidões humanas formadas historicamente, isto é, o processo de apropriação é, ao mesmo tempo, um processo de educação. Nas palavras de Leontiev (1978, p. 267),

Podemos dizer que cada indivíduo aprende a ser homem. O que a natureza lhe dá quando nasce não lhe basta para viver em sociedade. É-lhe ainda preciso adquirir o que foi alcançado no decurso do desenvolvimento histórico da sociedade humana.

De acordo com o autor acima, o processo de desenvolvimento histórico da sociedade humana está indissociável do processo de educação, uma vez que é por meio da ação educativa que ocorre a transmissão, às novas gerações humanas, das produções culturais consolidadas ao longo do tempo histórico. Assim sendo, ao nascer o homem necessita apropria-se do legado histórico-cultural deixado pela geração precedente como condição indispensável para tronar-se, também, um ser histórico e social. Esse processo ocorre por meio das relações socioculturais propiciadas pela educação.

Essa tese central da THC, de que o homem se humaniza nas relações sociais, traz implicações fundamentais ao processo pedagógico da educação escolar, pois toda atividade educativa possui em si uma intencionalidade, ou seja, não há atividade educativa escolar sem uma finalidade anteriormente pensada. A educação escolar tem por objetivo propiciar o processo de apropriação dos conhecimentos historicamente produzidos pela humanidade às novas gerações e, assim, contribuir efetivamente para a elevação do nível sociocultural dos sujeitos históricos, tendo em vista o processo de humanização.

Nesse contexto, a responsabilidade social da instituição escolar consiste em propiciar condições didático-pedagógicas adequadas ao processo de apropriação e potencialização do nível cultural dos sujeitos, bem como contribuir para a transformação da realidade socioeconômica, política e cultural por meio da conscientização crítica acerca da sociedade em que está inserido aprendizagem dos conhecimentos sociohistóricos são compartilhados intencionalmente no contexto escolar e promovem o processo de desenvolvimento das capacidades, habilidades e aptidões humanas.

A educação escolar planejada e organizada de forma intencional pode possibilitar o desenvolvimento da criança ao ativar processos intrapsíquicos que resultam na formação das capacidades de aprendizagem. Sendo a aprendizagem a capacidade necessária para promover o processo de desenvolvimento na criança das características intrinsecamente humanas formadas historicamente (VIGOTSKII ${ }^{3}$, 2012). A partir desse pressuposto podemos considerar que o ensino escolar necessita estar à frente das capacidades de aprendizagens da criança, impulsionando o processo de desenvolvimento e formação de qualidades psíquicas superiores.

Esse pressuposto nos leva a refletir sobre a Lei Geral do Desenvolvimento Humano elaborada por Vygotski (1995, p. 150 - tradução nossa) de que "Toda função no desenvolvimento cultural da criança aparece em cena duas vezes, em dois planos: no plano social e depois no plano psicológico, a princípio entre os homens como categoria interpsíquica e logo no interior da criança como categoria intrapsíquica".

3 Diante da diversidade de formas de registro gráfico do nome do autor L. S. Vygotski utilizamos, nas citações deste trabalho, a forma gráfica original apresentada nas diferentes obras. 
Vygotski (1995) revela que o desenvolvimento da criança ocorre por meio da formação de dois processos interligados: o primeiro de ordem biológica, espontânea e natural, denominado de processo psíquico inferior e/ou elementar; o segundo de ordem social, histórica e cultural, denominado de processo psíquico superior.

O segundo processo dá origem às estruturas complexas, ou seja, às funções psíquicas superiores, que se desenvolvem com a apropriação da cultura pelo sujeito como, por exemplo, a linguagem oral, a leitura, a escrita, o desenho, as operações matemáticas, o pensamento lógico, atenção voluntária e formação da conduta. Isto é, apropriar-se das produções culturais produzidas pelas e nas relações humanas potencializa o desenvolvimento e a formação de novas funções psíquicas superiores e a autorregulação de conduta do sujeito.

Os dois processos de formação e desenvolvimento humano do sujeito histórico são distintos, porém ocorrem de forma simultânea, não linear e, ao se apropriar dos bens culturais, também promove a criação e o desenvolvimento de novas funções psíquicas superiores e formações de novas condutas humana, como ressalta Vygotski (1995, p. 34, tradução nossa):

[...] No processo de desenvolvimento histórico, o homem social modifica os modos e procedimentos de sua conduta, transforma suas inclinações naturais e funcionais, elabora e cria novas formas de comportamento especificamente culturais.

Assim sendo, Vygotski (1995) ressalta, na Lei Geral do Desenvolvimento Humano, que o processo de apropriação cultural pela criança ocorre, primeiramente, nas relações interpessoais, ou seja, na esfera de interação social e, posteriormente, na relação intrapsíquica - individual favorecida pela educação. Daí a importância da formação das qualidades psíquicas superiores desencadeadas pelo processo de educação, tendo em vista o desenvolvimento e humanização da criança.

Sabendo que a criança constitui-se ser humano nas relações socioculturais que estabelece com o outro, o ambiente escolar deve ser um espaço de potencialização das interações sociais e culturais entre as crianças e dessas com os adultos, tendo em vista possibilitar o desenvolvimento das funções psíquicas superiores, a apropriação e objetivação do conhecimento histórico-científico. A interação sociocomunicativa entre os sujeitos do processo de ensino e aprendizagem favorecido na escola e na sociedade incide no nível de desenvolvimento psíquico da criança num dado momento histórico de sua vida. (VIGOTSKI, 1996).

Nesse sentido, far-se-á necessário que a criança, desde o início do processo de escolarização, mantenha interação social umas com as outras, conviva em contextos significativos de aprendizagem dos conhecimentos históricos e culturais. Conforme ressalta Vygotski (1995), o processo de aprendizagem ocorre sempre de maneira cooperativa, ou seja, em colaboração com outros sujeitos mais experientes, a partir de diferentes formas de interação humana.

O papel principal do professor consiste em conduzir o processo pedagógico como sujeito responsável em planejar, organizar e coordenar situações adequadas de ensino e aprendizagem favoráveis à formação e desenvolvimento da criança, pois o bom ensino favorece o processo de aprendizagem e, a aprendizagem, impulsiona o desenvolvimento do aprendiz (VYGOTSKI, 1995). Desse modo, consiste ao professor conhecer os níveis de desenvolvimento integral da criança para poder melhor planejar, organizar e intervir junto ao processo de ensino e aprendizagem, tendo em vista o seu pleno desenvolvimento humano. 
Ao conhecer os níveis de desenvolvimento real da criança, sabendo o que ela já aprendeu e consegue realizar sozinha, o professor pode planejar as ações pedagógicas que estejam à frente dessas capacidades e que favoreçam novas aprendizagens, de novos saberes históricos e culturais. Isto é, o professor favorece o desenvolvimento potencial da criança, ou seja, conduz à superação do nível de realização com auxílio do outro ao avanço ao novo nível de potencialidade da aprendizagem e desenvolvimento, sendo capaz de realizar a atividade de forma autônoma e independente - sozinha.

A THC traz em seus pressupostos implicações fundamentais ao processo de ensino e aprendizagem no contexto escolar, pois cabe à educação a responsabilidade de propiciar as condições necessárias ao desenvolvimento do processo de humanização. Sendo assim, "Estabelecer o nível de desenvolvimento real é uma ação fundamental e indispensável para resolver todas as questões práticas relacionadas à educação e aprendizagem da criança [...]" (VYGOTSKI, 1995, p. 265-266 - tradução nossa). O campo de atuação pedagógica do professor junto à aprendizagem da criança consiste em identificar e intervir intencionalmente em sua zona de desenvolvimento eminente.

A seguir, discutiu-se sobre as implicações dos pressupostos da THC ao processo de ensino e aprendizagem da leitura no espaço escolar na perspectiva da construção do sentido discursivo da linguagem escrita.

\section{Apropriação da leitura como prática de construção de sentido da linguagem escrita na perspectiva da Teoria Histórico-Cultural}

A partir dos pressupostos da THC e suas implicações no processo de humanização, podemos considerar que a Educação, em específico a educação escolar, constitui-se como condição indispensável ao processo de criação e desenvolvimento das capacidades essencialmente humanas.

Nesse contexto, em relação ao ensino e aprendizagem da leitura na escola, promover o processo de desenvolvimento das funções psíquicas superiores da criança diz respeito à formação de leitores críticos capazes de ler e compreender o sentido da linguagem escrita por meio de suas próprias "lentes". Sabendo que o desenvolvimento das funções psíquicas superiores é formado a partir das relações de interação estabelecidas entre os sujeitos e destes com os elementos culturais, torna-se necessário que o processo de ensino e aprendizagem da leitura no espaço escolar seja, desde o início da escolarização, fundamentado em efetivas atividades de leitura, no uso de diferentes gêneros textuais que realmente circulam nas práticas sociais e que as crianças tenham acesso por meio da mediação do professor e/ou de outro parceiro mais experiente.

Conforme Vygotski (1995), a aprendizagem acontece sempre em colaboração entre os sujeitos, tendo em vista a interação intencional propiciada pela prévia organização e definição de objetivos estabelecidos pelo professor. Assim sendo, cabe ao ele a tarefa de planejar, organizar e direcionar as diferentes situações de ensino em sala de aula, tendo em vista contribuir para com o desenvolvimento integral do educando, pois somente o bom ensino favorece a aprendizagem e este impulsiona o desenvolvimento humano.

Desse modo, o professor necessita saber sobre os conhecimentos de que a criança já se apropriou e o que são capazes de apropriar para poder elaborar situações significativas de ensino e promover a aprendizagem, pois antes da criança chegar à escola já vivenciou muitas experiências e se apropriou de inúmeros conhecimentos históricos que necessitam ser reconhecidos, valorizados e ampliados. 
Em relação ao processo de ensino e aprendizagem da leitura, Vygotski (1995) ressalta que não lemos os sons das letras e palavras, mas, sim os sentidos que as palavras representam no momento histórico que são constituídas. Daí ser necessário que o ensino da leitura esteja pautado nas condições socioculturais concretas de vida das crianças, superando práticas de decodificação mecânica e oralização da linguagem escrita ainda tão frequente nas escolas.

Em pleno século XXI, as instituições escolares ainda insistem em ensinar a ler como se a prática da leitura e da escrita fossem processos distintos, pois primeiro ensina-se as técnicas da codificação - escrita - para, só depois, ensinar a decodificação das letras e palavras - leitura, ou seja, ensina-se apenas o funcionamento do sistema de escrita e não as situações reais de utilização da língua viva, mediatizada por signos e símbolos culturais complexos existentes nas práticas sociais concretas. (VYGOTSKI, 1995).

De acordo com Vygotski (1996), a leitura não pode ser reduzida à produção de imagens correspondentes a todos os objetos mencionados na frase lida, nem mesmo na reprodução do nome correspondente à fonética da palavra - pauta sonora da grafia da escrita. Para o autor, a leitura consiste em uma atividade complexa que possibilita ao leitor operar o próprio movimento - rápido ou lento - dos olhos no deslocamento da atenção pelos diferentes pontos de interesse encontrados na escrita durante o ato de ler, isto é, no processo de estabelecer a relação entre as partes e o todo na formação do sentido global do discurso escrito/lido.

Promover o desenvolvimento dessa capacidade e habilidade de operar ativamente na construção de sentido, mobilizar os pontos de atenção e estabelecer as relações entre as partes e o todo significa possibilitar o processo de formação da conduta do leitor, pois não lemos e oralizamos palavras isoladas, mas, sim de forma focalizada e seletiva todo o conjunto de palavras conforme sua significação do processo de construção do sentido da escrita. Vigotski (1998, p. 150) ressalta que "uma palavra sem significado é um som vazio; significado, portanto, é um critério da palavra, seu componente indispensável".

Assim sendo, o autor distingue significado e sentido, pois uma palavra só possui significado no contexto sociocultural que a constitui e o significado é incorporado pelo sentido. O significado é estável, pois não se altera uma vez que consiste na própria palavra vista no seu aspecto interno, sendo o sentido passível de alteração de acordo com o contexto sociocultural. (VIGOTSKI, 1996).

Assim sendo, a atividade de leitura possibilita operação cognitiva do leitor com palavras que são significados estáveis que, conforme o contexto sociocultural, pode apresentar sentidos diferentes. Contudo, na prática escolar a criança precisa vivenciar experiências de leitura com textos reais, tendo em vista a construção de sentido discursivo a partir da significação do símbolo gráfico visual da linguagem escrita. Ao reconhecer apenas o aspecto sonoro da linguagem escrita, a escola destitui da palavra a sua essência, tornando-a apenas um som vazio, sem significação que impede a criança de construir sentido e intensifica o ensino da leitura de forma mecânica, dissociada da linguagem escrita.

O processo de ensino e aprendizagem da leitura pelo professor na escola precisa propiciar a criança condições para que possa, verdadeiramente, atribuir sentido à linguagem escrita, bem como desenvolver a necessidade de leitura como prática indispensável à sua formação humana. Daí ser um desafio para a escola frente à problemática de ensino e aprendizagem da leitura, pois é de fundamental importância criar na criança a necessidade de aprendizagem efetiva, ou seja, de práticas de leitura de textos que tenham sentido, motivando-as para as atividades desenvolvidas dentro e fora da sala de aula. 
O processo de ensino e a aprendizagem da leitura no espaço escolar precisam ser organizados e planejados intencionalmente pelo professor, tendo em vista o desenvolvimento das funções psíquicas superiores. Cabe a este propiciar situações de práticas de leitura que despertem na criança o gosto e a necessidade de leitura. Para isso, será preciso ofertar às crianças acervo literário diversificado, com diferentes suportes de diversos gêneros textuais em circulação social que motivem seu envolvimento com a prática da leitura como elemento cultural.

De acordo com Vigotskii (2012), por ser a leitura um elemento cultural complexo, seu aprendizado pela criança não ocorre de forma espontânea, mas precisa ser ensinada a ela pelo professor por meio de atividades efetivas, vivenciadas nas práticas socioculturais de usos da leitura e da escrita. Assim sendo, de acordo com os pressupostos da THC, torna-se claro o papel da educação na formação do leitor, há a iminente necessidade de interação social entre os sujeitos da aprendizagem - crianças entre si e com o professor - como motivos que impulsionam o desenvolvimento do processo de apropriação e objetivação da leitura como elemento cultural complexo.

Nesse sentido, com base nos pressupostos da THC, podemos considerar que a formação ativa do sujeito leitor se desenvolve por meio do processo de construção de sentido da linguagem escrita pela própria criança, no contexto de acesso e usos dos diferentes gêneros textuais escritos existentes na sociedade e apropriados e objetivados pela criança no contexto escolar.

\section{A concepção teórico-metodológica de ensino e aprendizagem da leitura de Jean Foucambert na perspectiva da formação do leitor crítico}

Jean Foucambert (1994), sujeito de origem francesa é um estudioso crítico do processo de leitura nas práticas de escolarização da criança. O autor ressalta que a Revolução Industrial se constituiu em um marco histórico no processo de popularização da escola e, consequentemente, na redução na condição de analfabetismo. Entretanto, não houve um crescimento na popularização da leitura. Diante disso, cabe a nós pesquisadores e professores questionarmos: por que e como é possível tal contradição?

O autor nos alerta de que, ao alfabetizar as pessoas, a escola tem se limitado a garantir a transmissão direta de técnicas de decifração, fato que não contempla a real necessidade de socialização e contextualização do saber histórico produzido e disseminado de maneira desigual nas sociedades, principalmente dentro e fora do espaço escolar, pois a escola ainda apresenta equívocos na prática pedagógica no sentido de confundir o saber ler com a capacidade de oralização das palavras.

No século XIX e início do século XX havia o predomínio da Retórica na formação do aprendiz, portanto, a leitura em voz alta fazia parte das práticas de ensino e aprendizagem escolar do uso da língua, especialmente da prática da oralidade. Saber decifrar e saber ler constituem-se práticas escolares totalmente diferentes, com implicações político-pedagógicas distintas na sociedade. Saber decifrar consiste praticamente no processo de tradução do texto escrito para a linguagem oral para ser compreendido pelo leitor. Todavia, saber ler, consiste em um ato essencial para a tomada de conscientização das ações do leitor acerca da leitura como ato social e político. (FOUCAMBERT, 1994).

Nessa perspectiva, a leitura consiste em uma linguagem específica para os olhos, totalmente independente da linguagem oral que visa constituir apenas uma representação oral do registro escrito, enquanto a leitura constitui-se como processo ativo de atribuição de sentido de significados à linguagem escrita pelo leitor. (FOUCAMBERT, 1994). 
O autor esclarece que a distinção entre linguagem oral e linguagem escrita no processo de ensino e aprendizagem da prática de leitura é sempre ignorada pela escola, pois quando se "ensina a ler", está apenas transmitindo técnicas de decifração, ou seja, de conversão/decodificação das letras do alfabeto em sons e, não se propicia o processo de atribuição de sentido do texto pelo próprio leitor.

O autor ainda nos apresenta outra distinção entre a linguagem oral e a linguagem escrita no processo de escolarização da leitura. A linguagem oral (oralização) apresenta-se de forma linear, pois nela "é obrigatório a pronúncia das palavras na ordem em que se apresentam" Foucambert (1994, p. 6). Entretanto, quando realizamos a leitura exploramos a escrita por meio da movimentação dos olhos que não ocorre de maneira linear e uniforme, pois esses dão saltos bruscos e descontínuos onde pausas (curtas e/ou longos) nos permitem a percepção dos sentidos, pois conforme Foucambert (2008, p. 64- 65, grifo do autor):

[...] Ao longo da fixação, o olho não percebe uma justaposição, mas um conjunto [...] o olho não percebe, portanto, letras que o cérebro pode transformar em sons para constituir conjuntos sonoros portadores de sentidos; o olho percebe conjuntos de signos que podem ser iguais ou superiores às palavras e que não coincidem necessariamente com elas!

O ato de possibilitar ao leitor coordenar o processo de percepção dos conjuntos de signos para atingir os seus objetivos e, assim, estabelecer o ritmo, o conteúdo e a forma de leitura. "Aquele que lê sabe por que e, portanto, decide como fazê-lo [...]" (FOUCAMBERT, 1999, p. 102).

O deciframento é, portanto, um mecanismo difícil de ser empregado e só funciona realmente bem se a palavra já tiver sido lida, o que limita, confessemos, seu interesse na aprendizagem da leitura! [...] para se atribuir um significado a uma forma escrita, identificando sua forma oral que lhe correspondente, é necessário evidentemente que essa forma oral seja reconhecida pelo seu significado, que tenha já um significado [...]. Em outras palavras, o deciframento não é uma solução universal [...] (FOUCAMBERT, 2008, p 74 - grifo do autor).

O ato de decifração sem o reconhecimento da palavra escrita e identificação de sua correspondência oral não pode, jamais, ser reconhecido como ato de leitura, pois emitir sonoridade de palavras não compreendidas culturalmente não se constitui de fato, atividade de leitura. Portanto, a prática do processo de deciframento torna-se ação inútil frente à valorização da oralidade como base de ajustamento ao processo de escrita.

O ato de leitura não poder ser restrito ao ato do deciframento uma vez que a criança, leitora iniciante, necessita, a nosso ver, de um repertório cultural, ainda não vivenciado, para estabelecer a compreensão do sentido discursivo, sabendo que a decifração ocorre somente quando as palavras escritas são reconhecidas e compreendidas pelo sujeito leitor. Portanto, para decifrar é preciso, antes, saber a ler.

Na perspectiva do deciframento, ler seria, apenas, extrair a sonoridade das palavras escritas, ou seja, oralizar o escrito. No entanto, o autor defende a tese de que a leitura diz respeito ao processo de compreensão e apreensão de um sentido do discurso escrito. Assim sendo, leitura "[...] diz necessariamente aparecimento de uma compreensão e apreensão de um sentido, ao menos compatível com a vontade de significação do texto [...]" (FOUCAMBERT, 2008, p. 75).

A leitura, na visão foucambertiana, consiste em um processo de atribuição de significados ao discurso escrito e se apresenta como uma linguagem para os olhos, desvinculada da linguagem oral. A linguagem escrita constitui-se como base para o desenvolvimento e transformação do conhecimento da língua, pois as palavras novas incorporadas ao vocabulário são conhecidas primeiramente na escrita, pela maioria das crianças leitoras. 
Também, é pela escrita que os sentidos das palavras vão, gradativamente, sendo compreendidos por meio dos "significados" até atingir um nível de "operacionalidade" e serem utilizados na oralidade, mesmo com suas possíveis distorções e, corrigida tais distorções orais, são armazenadas na memória como elemento diferenciador entre os significados. Desse modo, a escrita manifesta como elemento cultural capaz de favorecer o processo de desenvolvimento humano por meio da apropriação da atividade de leitura numa perspectiva dialética.

Foucambert (2008, p. 76) nos apresenta uma questão para reflexão ao questionar sobre como ocorre o processo de operacionalização e apreensão das informações apresentadas nos conjuntos de signos escritos em cada fixação dos olhos, uma vez que a compreensão em leitura não depende da oralização e da decifração? Para buscar resposta a essa questão, o autor discuti dois processos indissociáveis: a identificação e a antecipação.

No processo de identificação o sujeito leitor já tem em sua memória um acervo de palavras escritas que lhe possibilita associar o significado à forma. Logo, no processo de antecipação, o contexto, o interesse e as últimas palavras lidas direciona o leitor à antecipação da palavra ou conjunto de palavras que encontrarão à frente dos olhos. Isto é, "ler é verificar a exatidão de uma antecipação" (FOUCAMBERT, 2008, p. 76).

Para o autor, as operações de identificação e antecipação das formas escritas não ocorrem apenas sobre palavras isoladas, mas sim, sobre as relações e as ligações existentes entre elas, estabelecidas em um contexto sociohistórico da atividade da linguagem escrita, ou seja, a significação se dá com base em uma organização de conjuntos de signos culturais.

A compreensão do discurso escrito resulta do processo de operacionalização da identificação e antecipação que o sujeito leitor estabelece sobre os significados do conjunto da organização discursiva, ou seja, do discurso escrito materializado simbolicamente como elemento cultural que veicula nas práticas sociais como informação, ideia, fato ou acontecimento sociohistórico e cultural.

A operação de antecipação encontra-se implícita na capacidade de percepção ativa do ser humano, portanto, não é exclusiva da leitura. Nesse contexto, a percepção é uma ação criativa que envolve atividade de pesquisa, projeção de informações já obtidas de acordo com os interesses do sujeito que percebe a escrita. A leitura é o equilíbrio entre o processo de identificação e de verificação da antecipação das palavras enquanto organização discursiva desenvolvida pelo leitor.

Desse modo, a identificação e a verificação da antecipação sob a percepção da escrita de acordo com os conhecimentos subjetivos do leitor, pode tornar o texto escrito como "fácil" ou de "difícil" reconhecimento discursivo - compreensão. A antecipação faz parte do processo de leitura, pois a atribuição de significado do conjunto de palavras interrelacionadas é guardada na memória e auxilia a antecipação de palavras novas, ancorado no significado que criou, assim, as palavras novas são incorporadas as já compreendidas, contribuindo para a construção de novos significados de outras palavras, ou seja, de unidades de sentidos discursivos (FOUCAMBERT, 2008, p.79).

Nessa perspectiva, o processo de reconhecimento da escrita pode ser considerado como o processo de "apreensão de indícios" que acontece de formas variadas dependendo da percepção da escrita pelo sujeito. Contudo, o processo de reconhecimento constitui-se a âncora a atividade de antecipação e atribuição de significado à forma dos conjuntos de signos da escrita, ou seja, à atribuição do sentido discursivo (FOUCAMBERT, 2008, p. 81). 
Dentre os equívocos da educação escolar em relação à leitura como, por exemplo, o deciframento já mencionado, o autor ainda ressalta o reconhecimento e valorização de tipos de leitura: em voz alta e a silenciosa. A leitura em voz alta consiste na prática predominante desenvolvida na escola, sendo a leitura silenciosa secundária, pois o objetivo central da escola consiste em desenvolver o processo de deciframento como mecanismo de leitura, pois, para ser reconhecida, a palavra deve ser pronunciada em voz alta, desenvolvendo primeiramente a leitura oral de forma fluente, mais elaborada para, posteriormente, internalizar a fala (oral) por meio da leitura silenciosa. Assim sendo, a escola prioriza a leitura em voz alta em detrimento da leitura silenciosa.

Entretanto, esse processo não se apresenta tão eficaz dessa forma, pois a leitura em voz alta requer que o leitor já tenha domínio das capacidades e habilidades de compreensão do discurso escrito, desenvolvido por meio da leitura silenciosa que propicia o processo de compreensão. Nas palavras de Foucambert (2008, p. 83 - grifo do autor):

A leitura em voz alta não é, portanto, uma etapa em direção à leitura silenciosa; é uma fase muito elaborada que já supõe um perfeito domínio da leitura; ela não permite aprender a ler, supõe que já se sabe ler. Deferentemente do que sempre se diz, a leitura silenciosa não é uma leitura em voz alta que se interioriza, é a leitura em voz alta que é uma leitura silenciosa que se sonoriza [...].

Na verdade, de acordo com o autor, quem conduz o ato de ler é a leitura silenciosa e não a em voz alta, pois antes de pronunciar oralmente o leitor competente já operacionalizou o processo de identificação das palavras e conjuntos de signos escritos por meio das fixações dos olhos, portanto, identificando os sentidos discursivos e antecipando o reconhecimento ideográfico dos signos encontrados a frente no registro escrito. Todo esse processo ocorre de forma complexa e muito rápida, necessitando de um perfeito domínio do ato de ler. Assim, sendo, a leitura em voz alta, pronunciada, consiste na oralização, ou seja, na proferização do discurso escrito, pois a compreensão do sentido do texto já fora desenvolvida pela atividade da leitura silenciosa que "utiliza" a voz para oralizar ou proferir o discurso escrito.

Foucambert (2008) também nos ressalta dos riscos ao processo de ensino aprendizagem dos leitores pela escola considerar vários tipos de leitura: em voz alta e silenciosa. O autor, enfaticamente, defende que não há diferenciação nas formas de leitura, pois reconhece que há somente uma atividade de leitura. Desse modo, Foucambert (2008, p. 83 - grifo do autor) nos ressalta que:

[...] a leitura é uma ou ela não é; ela é essa possibilidade de ler lentamente, depressa, em voz alta, para obter informação, para se distrair; a leitura é todas essas possibilidades de uma só vez ou ela não é leitura. É necessário, portanto, defini-la a partir da atividade única comum a todas as formas: ler consiste em retirar antecipadamente informações da língua escrita para construir diretamente um significado.

Ao atingir o pleno domínio do processo de atividade de leitura a criança conquista autonomia para desenvolvê-la de acordo com sua preferência, desde que o sentido do texto seja construído. Portanto, ler define-se pelo processo de construção de sentidos discursivos a partir das significações dos signos escritos reconhecidos e identificados culturalmente pelo sujeito leitor. A concepção de leitura pode trazer implicações fundamentais ao processo de ensino e aprendizagem na escola.

A partir da definição de leitura defendida por Foucambert (1994; 2008), passaremos a refletir sobre o processo de formação da conduta leitora das crianças na escola, ou seja, sobre o modelo de ensino e aprendizagem da leitura que promove a competência e a conduta da criança leitora, para além do deciframento e apelo à oralização do escrito. 


\section{A concepção de leitura para Foucambert e as implicações pedagógicas no processo de ensino e aprendizagem escolar}

Ao considerar a leitura como processo de construção de sentidos discursivos, o autor nos apresenta uma nova abordagem didático-metodológica ao processo de ensino e aprendizagem no espaço escolar. O processo de ensino não se inicia apenas a partir da presença da criança na escola e nem termina quando essa conclui sua formação escolar. No entanto, cabe à escola propiciar as condições materiais e imateriais para assegurar o desenvolvimento desse processo que começa muito antes da criança chegar à escola.

A aprendizagem da leitura pela criança inicia-se a partir das vivências e experiências que estabelece nas diversas situações sociais de contato com a leitura, ou seja, nas relações de interação da criança com objetos de leitura existentes na sociedade. Quanto mais oportunidade de acesso e interação ativa com materiais de leitura, mais a criança apresenta condições favoráveis de desenvolvimento das capacidades e habilidades de ser leitor, isto é, não há uma idade pré-determinada para o início do desenvolvimento da leitura pela criança, mas sua relação com o meio sociocultural é de importância fundamental nos modos de ser leitor (FOUCAMBERT, 2008).

Desde o nascimento a criança encontra-se imersa ao mundo da cultura escrita e, evidentemente, vivencia práticas sociais de leitura, ou seja, vivencia os pais fazendo usos das práticas de leitura e escrita na vida em sociedade. As vivências da criança e suas experiências com as mais diversas práticas sociais de leitura e escrita favorecem o processo de significação funcional da leitura, essencial à formação da competência leitora. A aprendizagem da leitura pela criança não acontece predominantemente no espaço escolar, pois, na sociedade contemporânea, resulta das relações sociais devido à dinâmica da vida, bem como do processo de desenvolvimento científico e tecnológico.

No espaço escolar, cabe ao professor propiciar as condições necessárias para garantir a continuidade do processo de aprendizagem da atividade de leitura. Assim sendo, desde a educação infantil ele precisa apresentar à criança diferentes suportes da cultura escrita e, juntos, buscar interagir e desenvolver a significação funcional da prática da leitura. "O meio escolar deve permitir às crianças viver a aprendizagem da leitura como valor de comunicação" (FOUCAMBERT, 2008, p. 98).

Foucambert (1997) afirma que ler consiste em compreender os signos escritos e que essa atividade é realizada por cada sujeito por diferentes motivos e nos apresenta algumas das modalidades de motivação que impulsionam a criança a ler, discute e analisa o que cada uma delas tem em comum:

a) A unidade comum entre os motivos de leitura consiste na intencionalidade ao participar de um projeto que satisfaz seu interesse e objetivos;

b) A leitura exige que o leitor invista mais informações a mensagem lida do que a quantidade que extrai. O conhecimento que o leitor possui atrás dos olhos encontra com as informações à frente dos olhos, antecipa o procedimento de significação dos signos, isto é, os olhos direcionam a atenção do leitor para o que vai encontrar à frente do texto;

c) Na sequência, ocorre a experiência linguística, ou seja, da gramática do texto à da frase com a finalidade de constituir um conjunto organizado de operações intelectuais, formando uma linguagem para os olhos;

d) A relação do leitor com o projeto específico de leitura e a construção do modo de ler, tendo em vista atingir a satisfação pessoal, o prazer de ser leitor, ou seja, o nível de envolvimento do leitor com o objeto de leitura que caracteriza o ritmo e as formas de ler; 
e) A necessidade de escrever, de investigar e construir sentido ao texto escrito, desenvolver a autonomia de pensar, correlacionar o escrito com o mundo real por meio das conexões, construir o conhecimento abstrato e teórico;

f) Saber ler de referência como pressuposto didático-metodológico, tendo em vista a percepção das relações existentes entre os textos, ou seja, perceber que todo texto se constitui na relação discursiva com outros textos. Logo, também, toda escrita resulta da vivência de quem escreve, com base nas leituras já realizadas, portanto, produz uma escrita de referência, sustentada na leitura em rede. É pela leitura que se adentra no universo da cultura escrita. Assim, aprender a ler é fazer parte desse universo, que não pode separar os aspectos técnicos da prática de intertextualidade existente no processo de leitura e escrita.

Nesse contexto, o autor propõe a substituição do termo "alfabetização" pelo termo "leiturização", pois este permite abrir um universo de modos de pensar a partir da linguagem escrita.

Para Foucambert (1997), alfabetização na perspectiva da leitura consiste negar o ensino das técnicas de decifração, ou seja, de conversão das letras do alfabeto em pautas sonoras - oralização do escrito. Segundo o autor, o ensino da leitura na perspectiva da leiturização está relacionado à capacidade da criança atribuir sentido ao conjunto de signos culturais que vê a sua frente no ato de ler. O leitor é reconhecido como sujeito ativo no processo de construção e reconstrução dos sentidos discursivos na atividade de interação e significação do texto escrito. Assim sendo, a criança somente poderá ser considerada leitora quando desenvolver as capacidades de atribuição de sentidos ao discurso escrito, ser capaz de atribuir sentido à atividade de leitura.

Os modos de formação do leitor com base na construção e reconstrução dos sentidos discursivos de textos reconhecem e valorizam as experiências de leitura que a criança vivenciou na vida em sociedade, constituída pelos valores, crenças, atitudes e visão de mundo.

Na perspectiva interacionista de leitura, Foucambert (1997) ressalta a hipótese e de que a compreensão não seja apresentada como o resultado da atividade de leitura, mas constitui-se como a própria atividade em si, pois acontece na construção dos conteúdos semânticos e na abordagem das unidades gráficas de forma concomitante. [...] A compreensão é, nesse caso, um processo e não o resultado, "[...] é o processo de questionamento recíproco de um capital gráfico diante dos olhos e de um capital semântico atrás dos olhos. O resultado é a significação atribuída ao texto, à mudança que o texto provocou nas representações do leitor" [...] (FOUCAMBERT, 1997, p. 120).

Desse modo, a escrita pode ser considerada como uma linguagem para os olhos e a leitura como processo grafo-semântico, ou seja, uma troca direta entre as informações atrás e diante dos olhos no processo de construção e reconstrução dos sentidos discursivos. A compreensão do sentido discursivo do texto escrito caracteriza-se pela própria atividade de leitura, isto é, o ato de ler consiste no processo de compreender o discurso escrito de forma ativa, crítica e subjetiva. Portanto, há uma relação dinâmica entre o processo de significação do escrito e construção do sentido discursivo com base nas vivências socioculturais do sujeito leitor.

Em sala de aula o professor atua como sujeito do processo de mediação entre a criança e o objeto de leitura, criando necessidades e impulsionando a criança a realizar a leitura por meio de seus interesses e projetos de leitura individual e subjetiva, atividade que o leva a significação e construção de sentido discursivo a partir da produção escrita. Assim sendo, a atividade da leitura na escola requer envolvimento das crianças nas diferentes propostas de atividades, no planejamento e organização das condições necessárias ao desenvolvimento do processo de aprendizagem das capacidades de leitura pela criança. 


\section{Algumas considerações}

A reflexão sobre o processo de ensino e aprendizagem da leitura das crianças no contexto escolar exige uma abordagem teórica e metodológica fundamentada em princípios que a reconheçam como sujeito ativo e crítico no processo de aprendizagem e que tais capacidades e habilidades favoreçam o pleno desenvolvimento das condições humanas.

O conhecimento acerca do processo da aprendizagem da leitura no contexto escolar é de fundamental importância para promover intervenções pedagógicas adequadas. Isto é, conhecer o processo de aprendizagem da leitura pelo qual passa a criança constitui-se a base do processo de ensino na perspectiva do desenvolvimento e formação humana.

Nessa perspectiva, podemos perceber uma aproximação entre as concepções de leitura e o processo metodológico de ensino e aprendizagem da leitura nas duas abordagens teóricas apresentadas, ou seja, nos pressupostos da Teoria Histórico-Cultural e da concepção de Leiturização de Foucambert, pois ambas as abordagens concebem a criança como sujeito ativo no processo de apropriação e desenvolvimento da leitura no contexto escolar.

A atividade de leitura é concebida como processo de construção e reconstrução de sentido discursivo da produção escrita. O aspecto cultural representa a base do processo de significação dos conjuntos de signos que a criança encontra frente aos olhos e que são constatados com os conhecimentos já significados anteriormente e armazenados na memória que, no ato da atividade de leitura são acionados para significar o contexto global do texto, tendo em vista promover o desenvolvimento do processo de compreensão crítica e subjetiva do discurso escrito pelo leitor.

Nesse contexto, a leitura deixa de ser uma ação de deciframento e decodificação dos signos escritos - códigos - para ser considerada como produto do processo de interação entre o que a criança vê diante dos olhos e estabelece a conexão com que tem atrás dos olhos, ou seja, a leitura caracteriza-se como processo complexo da cultura humana.

Ao realizar o processo de percepção e significação cultural dos signos de compreensão do sentido discursivo a criança desenvolve, na perspectiva vigotskyana, as capacidades e aptidões essencialmente humanas, ou seja, as funções psíquicas superiores como, por exemplo, a leitura e a escrita, responsáveis, também, pela formação e desenvolvimento da inteligência e personalidade da criança.

De acordo com a Teoria Histórico-Cultural, o contexto histórico e social de vida da criança contribui significativamente para sua formação integral e atuação ativa e no processo de percepção e significação dos conhecimentos necessários à construção do sentido discursivo do produto de leitura. Nesse sentido, Foucambert (2008) também considera o contexto sociocultural como aspecto importante no processo de leiturização, pois, para o autor, esse processo possibilita à criança compreender o sentido discursivo do texto escrito a partir de sua própria experiência de vida, mobilizando seus conhecimentos culturais, suas crenças e valores individuais e coletivos.

A partir dos pressupostos teórico-metodológicos discutidos, o processo de ensino e aprendizagem da leitura no espaço escolar é reconhecido como atividade essencial ao desenvolvimento humano da criança. Cabe à escola constituir-se como espaço de circulação dos diferentes suportes e gêneros textuais necessários como objetos e produtos da atividade de leitura pela criança. Isto é, os materiais de leitura que a criança tem acesso na escola precisam ser reconhecidos por ela nas práticas socioculturais de leitura e escrita de sua vida cotidiana, havendo uma relação entre as vivencias de leitura e escrita da criança dentro e fora da escola. 
Desse modo, o professor assume a responsabilidade de planejar, selecionar e organizar as condições favoráveis para garantir a continuidade do processo de aprendizagem da leitura para além da idade escolar. Como ressalta Foucambert (2008), o processo de aprendizagem da criança inicia-se muitos antes da criança chegar à escola e, está por sua vez, precisa dar continuidade de modo que a criança seja envolvida emocionalmente pela leitura durante toda sua vida. Portanto, a atividade de leitura independe do processo de escolarização. Vygotski (1995) destaca que o desenvolvimento humano da criança resulta da interação que estabelece nas relações socioculturais vivenciadas em seu meio antes, durante e depois da educação escolar. Esse mesmo princípio é considerado por Foucambert em relação à aprendizagem da leitura.

O professor, portanto, precisa motivar a criança a desenvolver um projeto individual e subjetivo de leitura, ou seja, criar necessidades e interesses de leitura, tendo em vista buscar informações que possam trazer-lhes respostas às suas questões investigativas, que satisfaçam seus interesses

e curiosidades e lhes dá prazer na atividade de leitura. Assim sendo, o espaço escolar precisa ser mobilizador, motivador e criador de necessidades de leitura, na qual possa ofertar à criança diferentes suportes e gêneros de leitura, principalmente àqueles que circulam nas práticas socioculturais existentes na sociedade.

A partir da apropriação e objetivação teórico-metodológica da concepção de ensino e aprendizagem da leitura pelo professor, a criança torna-se sujeito ativo e crítico no processo de constituição e atribuição do sentido histórico-cultural ao discurso escrito. Desse modo, a atividade de leitura torna-se, de fato, reconhecida e valorizada como processo subjetivo de compreensão do discurso escrito como processo complexo da cultura humana.

\section{Referências}

LEONTIEV, Alexis Nikolaevich. O homem e a cultura. In: LEONTIEV, Alexis Nikolaevich. O desenvolvimento do psiquismo. Lisboa: Livros Horizonte, 1978, p. 259-284.

LÜDKE, Menga. ANDRE, Marli E.D.A. A Pesquisa em educação: abordagens qualitativas. 2 ed. Rio de Janeiro: E.P.U., 2013.

FOUCAMBERT, Jean. A leitura em questão. Porto Alegre: Artes Médicas, 1994.

FOUCAMBERT. Jean. A criança, o professor e a leitura. Porto Alegre: Artmed, 1998, p. 89-130.

FOUCAMBERT. Jean. Modos de ser leitor: aprendizagem e ensino da leitura no ensino fundamental. Curitiba: Editora UFPR, 2008, p. 61-103.

VYGOTSKI, Lev Semenovich. Obras Escogidas. Madrid: Visor, 1995. v. 3.

VIGOTSKI, Lev Semenovich. Obras Escogidas. Madrid. Visor, 1996. V.4.

VIGOTSKI, Lev Semenovich. Pensamento e linguagem. $2^{a}$ ed. São Paulo: Martins Fontes, 1998.

VIGOTSKII, Lev Semenovich. Aprendizagem e desenvolvimento intelectual na idade escolar. In: VIGOTSKY, Lev Semenovich, LURIA, Alexander Romanovich, LEONTIEV, Alexis Nikolaevich. Linguagem, desenvolvimento e aprendizagem. São Paulo: Ícone, 2012, p.103-117.

Recebido em: 01/03/2021

Aceito em: 08/05/2021 